\title{
MARCO LEGISLATIVO DEL ACOGIMIENTO FAMILIAR
}

\author{
ANA ROSSER LIMIÑNANA
}

Psicóloga de la Unidad de Adopción de la Conselleria de Bienestar Social. Alicante.

\section{RESUMEN}

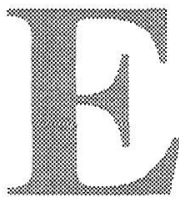

1 presente artículo hace un recorrido sobre la legislación existente en los ámbitos internacional, nacional y autonómico (Comunidad Valenciana) respecto al acogimiento familiar, su evolución, avances y aspectos pendientes de acometer.

\section{PALABRAS CLAVE}

Acogimiento familiar, Legislación.

\section{INTRODUCCIÓN}

La adopción y el acogimiento familiar se enmarcan dentro de las medidas de protección a la infancia que se vienen desarrollando tanto a nivel internacional como nacional cuando se detectan casos de problemática socio-familiar y en los que se plantea la conveniencia de que el niño sea acogido por una determinada familia de forma transitoria o permanente, dado que su familia no puede o no quiere hacerse cargo de las obligaciones que conlleva ser padres.

Aunque existen antecedentes históricos importantes sobre la figura del acogimiento de menores, la preocupación por regular esta medida de protección infantil se instaura con fuerza en Europa a partir de la segunda mitad del siglo XX, y especialmente en sus últimas décadas, reflejándose en el desarrollo normativo de los distintos países, aunque a ritmos diferentes y con matices.

En general, la normativa sobre el acogimiento familiar, así como la promoción e intensificación de dicha figura se dieron como consecuencia de los numerosos estudios que evidenciaban los efectos negativos que producía la institucionalización de menores en su desarrollo personal y adaptación social. 
En España, como veremos más adelante, el marco legal del recurso empieza a vislumbrarse a finales de los años 80 , si bien habrá que esperar hasta 1996, con la publicación de la Ley Orgánica De Protección Jurídica Del Menor, para poder contar con un instrumento que reconozca plenamente y regule los aspectos legales del acogimiento familiar en todas sus formas.

\section{NORMATIVA LEGAL SOBRE ACOGIMIENTO FAMILIAR A NIVEL INTERNACIONAL.}

El hito principal, a nivel internacional, referente a la protección infantil lo encontramos con la Declaración De Los Derechos Del Niño que proclamó Naciones Unidas en su Resolución 1386 de 20 de noviembre de 1959, particularmente sus principios 2, 4 y, especialmente, el 6, que establece que, siempre que sea posible, el niño deberá crecer al amparo y bajo la responsabilidad de sus padres y, en todo caso, en un ambiente de afecto y seguridad moral y material.

Destaca, posteriormente, la Resolución (77) 33 de 3 de noviembre de 1977 del Consejo de Europa sobre Acogimiento de Menores, que viene a recoger los principios por los que debe regirse este recurso.

Por otra parte, en la Convención de las Naciones Unidas sobre los Derechos del Niño del 20 de septiembre de 1989, cuyo instrumento de ratificación por parte de España fue publicado en el B.O.E. de 30 de diciembre de 1990, se recogerá nuevamente el derecho de los menores a no ser maltratados y a ser protegidos por las entidades públicas del estado.

Finalmente, el Convenio de la Haya, relativo a la protección del niño y a la cooperación en materia de adopción internacional de 20 de mayo de 1993, cuyo instrumento de ratificación por parte de España fue publicado en el B.O.E. de 1 de agosto de 1995, vendrá a regular la colaboración entre los distintos estados contratantes y la normativa en materia de adopción internacional, garantizando que se preservará en las mismas el interés del menor y previniendo la sustracción, venta y tráfico de niños.

\section{NORMATIVA LEGAL SOBRE ACOGIMIENTO FAMILIAR A NIVEL ESTATAL.}

La constitución española de 1978 recoge, fundamentalmente en el artículo 39 la protección que dispensa tanto a la familia como al me- 
nor, siguiendo la línea de interés que con respecto a esta materia viene reflejándose en los distintos acuerdos internacionales.

La norma constitucional obliga a los poderes públicos a asegurar una protección a la familia, como marco idóneo donde se desarrolla el individuo y donde debe ser atendido.

El apartado 2 del artículo 39 del texto constitucional establece la necesidad por parte de los poderes públicos de asegurar una protección al menor mas allá del deber asistencial que tienen los padres con respecto a sus hijos. En consecuencia, los niños deben gozar de una protección, no sólo por parte de sus padres, sino también a través de los distintos mecanismos que establezcan los organismos públicos competentes en materia de asistencia y defensa del menor.

A nivel legislativo, en el ámbito estatal, no será hasta noviembre de 1987, con la ley $21 / 87$, por la que se modifican determinados artículos del Código Civil y de la ley de Enjuiciamiento Civil en materia de adopción, cuando se regulen las medidas de protección infantil y en concreto el acogimiento y la adopción, si bien estas ya contaban con un abordaje jurídico desde 1937.

Las metas claves de la ley 21/87 fueron:

- La desjudicializacion de las primeras etapas de protección, agilizando su aplicación.

- La potenciación del papel de las entidades públicas a través de los servicios sociales.

- La profundización de la idea de un Ministerio Fiscal, defensor real del menor.

- La prioridad del tratamiento del menor en su propia familia.

A partir de estos principios, la ley 21/87 introdujo grandes cambios en el ámbito de la protección del menor:

- Permitiendo la asunción automática por parte de la entidad publica de la tutela de los menores que se encontraran en situación de desamparo (posibilidad que, hasta entonces, sólo era potestad del juez).

- Considerando la adopción como un elemento de plena integración familiar.

- Configurando el acogimiento familiar como una nueva institución de protección.

- Regularizando y simplificando el procedimiento, para lo que se modificaron los artículos 172 y siguientes del Código Civil.

La ley orgánica 1/96 De Protección Jurídica Del Menor vendrá a cubrir algunas lagunas de aquella ley, a la vez que pretende dar respuesta a las nuevas necesidades y demandas que han ido surgiendo desde la publicación de la anterior. 
En este sentido, en el tema que nos ocupa, aporta las siguientes novedades:

- Diferencia explícitamente el acogimiento familiar y el acogimiento residencial como distintas formas de ejercer la guarda de los menores.

- Flexibiliza la acogida familiar para dar respuesta a las distintas circunstancias que concurran sobre el menor y a la finalidad del acogimiento, distinguiendo tres modalidades:

- Simple, cuando se establece una medida transitoria.

- Permanente, para dotar de estabilidad familiar a los menores que no pueden acceder a la adopción ni es posible su retorno a la familia de origen.

- Preadoptivo, con vistas a su adopción.

- Permite a la entidad pública acordar un acogimiento provisional en la familia, aun cuando los padres no consientan o se opongan y en tanto se produzca resolución judicial.

- En materia de adopción, internacional, introduce la exigencia del requisito de idoneidad de los adoptantes y regula el papel de las entidades mediadoras en el ámbito de la adopción internacional.

\section{IV.NORMATIVA LEGAL SOBRE ACOGIMIENTO FAMILIAR EN LA COMUNIDAD VALENCIANA.}

En el ámbito autonómico, el acogimiento familiar ha sido regulado por la siguiente normativa legal:

4.1. La orden del 20 de marzo de 1986 de la Conselleria de Treball i Afers Socials, por la que se establece el recurso de familias educadoras en la Comunidad Valenciana; surge con carácter pionero a nivel nacional, tras las experiencias catalanas, para regular los acogimientos familiares.

Observamos en esta orden que:

- Ya delimita las características del recurso de acogimiento familiar como medida de protección temporal en situaciones de riesgo.

- Tiene como principios rectores:

- la voluntariedad de las partes.

- la cercanía entre las familias de origen y educadora.

- la temporalidad.

- Hace pivotar el recurso sobre las Secciones de Familia, Infancia y Juventud de las Direcciones Territoriales de la Conselleria de Treball i Afers Socials. 
4.2. E1 Decreto $23 / 1988$ de 8 de febrero del Consell de la Generalitat Valenciana, de medidas de protección de menores en situación de desamparo en la Comunidad Valenciana, desarrolló más ampliamente el recurso dentro del ámbito de las medidas de protección, pudiéndose destacar del mismo los siguientes aspectos:

- Se atiene a los términos marcados por la ley 21/87.

- Asume la orientación, principios, reglamentación y gestión de la orden de 1986.

- Procura la municipalización de la gestión, en aras a su descentralización.

- Señala como requisitos para su aplicación:

- la jerarquización de los recursos, agotando previamente las mediadas que permitan mantener al menor en su medio natural.

- valorar la idoneidad de las personas acogedoras.

- Añade, respecto a la orden anterior:

- una organización funcional y competencial en la aplicación de las medidas.

- la colaboración de las instituciones de integración familiar.

- la determinación en la resolución del tiempo y de la cuantía económica.

- la atribución de poder resolutivo a las Comisiones Mixtas.

4.3. El Decreto $31 / 1991$ de 18 de febrero, que modifica el Decreto 23/88 de Medidas De Protección De Menores En Situación De Desamparo En La C.V., pasará a atribuir a las Comisiones Mixtas de familias Educadoras la emisión de la propuesta técnica al Jefe de Area de Servicios Sociales.

4.4. La ley 7/1994 de 5 de diciembre de la Infancia, de la Generalitat Valenciana, se va a caracterizar porque:

- Pretende consolidar la política que desde los distintos sistemas con responsabilidad en materia de menores vienen implantándose en la Comunidad Valenciana, de forma integral y coordinada, indicando la necesidad y sentando las bases para la elaboración del Plan Integral de Atención a la Infancia.

- Contempla los cinco grandes programas de intervención según los cuales se articula el Plan de Ordenación de los servicios sociales en la C. Valenciana:

- Información.

- Accesibilidad.

- Cooperación.

- Convivencia.

- Reinserción. 
- Diferencia distintas modalidades de intervención, niveles primarios y especializados, en cada uno de los programas.

- Incluye el acogimiento familiar en el programa de convivencia, y diferencia el acogimiento familiar primario y el especializado, en función de que el mismo se realice en ámbitos próximos al entorno del menor (familia extensa, vecindario, etc.) o alejados del mismo, y de su finalidad (retorno o adopción).

\section{NORMATIVA DE SOPORTE.}

Existe, además, todo un cuerpo de normativa legal, tanto a nivel estatal como autonómico, que, sin referirse específicamente a la protección de la infancia, sí le sirve de soporte para poder llevar a cabo con éxito la misma, y que, fundamentalmente, engloba las siguientes leyes:

- La ley 8/1985 de Derecho a la Educación, que generaliza el principio de integración escolar.

- La ley 7/1985, reglamentada en Real Decreto $155 / 1996$ sobre derechos y deberes en España, que recoge los derechos de los extranjeros residentes en el país.

- La ley 14/1986 General de Sanidad, que propicia la universalizaron de la sanidad.

- La Ley 5/1989 de Servicios Sociales de la Comunidad Valenciana, que desarrolla el principio de normalización de la asistencia social.

- La ley 5/1997, que modifica la anterior en lo que respecta a la regulación del Sistema de Servicios Sociales en la Comunidad Valenciana.

\section{CONCLUSIONES.}

A la vista del recorrido realizado por la normativa legal que sustenta el recurso del acogimiento familiar como medida de protección infantil, podríamos aventurar las siguientes conclusiones:

1. No se han producido cambios relevantes en los principios y parámetros de actuación. Sorprende comprobar cómo las recomendaciones realizadas por el Consejo de Europa, en 1977, hace más de 20 años, siguen teniendo vigencia en la actualidad. Muchos de los aspectos allí recogidos no se han implementado en su totalidad hasta la fecha en los diferentes programas de protección infantil existentes, o no son tenidos en cuenta a la hora de aplicar el recurso del acogimiento familiar a las situaciones concretas, posiblemente 
no por desconocimiento de estos principios sino por la falta de recursos disponibles y/o la urgencia de las situaciones.

2. La ley de Protección Jurídica del Menor ha supuesto un avance tardío pero eficaz en cuanto al soporte legal que requerían diferentes aspectos de la puesta en práctica del acogimiento familiar, especialmente cuando no se contaba con el consentimiento de los padres y respecto a sus modalidades de aplicación en función de la finalidad del mismo.

3. A nivel autonómico, en la Comunidad Valenciana se ha producido, a partir de la ausencia de desarrollo de la Ley de la Infancia (Ley $7 /$ 94 de la G.V.) y su falta de concordancia con la ley 1/96, un estancamiento legal que se ha ido supliendo con instrucciones y circulares que no han llegado a cobrar cuerpo normativo hasta la fecha. En consecuencia, siguen estando sin regular aspectos tan importantes como:

- La adecuada coordinación entre las diferentes instancias cuyo centro de interés es el menor: educativas, sanitarias, etc.

- La implantación de programas integrales a nivel preventivo y de actuación en el medio donde se detectan las situaciones de riesgo.

- La creación de Equipos de Atención Especializada a nivel municipal o comarcal que permitieran el abordaje de las problemáticas de mayor complejidad técnica, desde el propio entorno en el que se producen.

4. Por otra parte, parece estarse produciendo un giro en cuanto al marco competencial que apunta hacia un intento de «recentralización» del control y la puesta en marcha de las medidas de protección, cuyo peso específico vuelve a recaer en las entidades de carácter autonómico o provincial, en detrimento de las municipales.

5. Finalmente, la reciente separación de los programas referidos a menores, a nivel competencial en la Comunidad Valenciana, entre las Direcciones Generales de Servicios Sociales y Familia y Adopciones respectivamente, parece estar dificultando todavía más la realización de planes de actuación sobre los menores que les permitan alcanzar una estabilidad familiar definitiva y lo menos traumática posible.

\section{BIBLIOGRAFÍA}

AGUILAR VENTURA, A., COGOLLOS RUBIO, Y. y CALERO JAÉN, C. (1992): Acogimiento familiar y familias educadoras en la Comunidad Valenciana. Generalitat valenciana. Conselleria de Treball i Seguretat Social. 
DE PAUL OCHOTORENA, J. y ARRUABARENA MADARIAGA, M.J. (1996): Manual de protección infantil. Masson. Barcelona.

IGLESIAS REDONDO (1996): Guarda asistencial, tutela ex lege y acogimiento de menores. CEDES editorial. Barcelona.

MARÍN GARCÍA DE LEONARDO, M.T. (1991): La tutela ex lege. La guarda y el acogimiento de menores en la Comunidad Valenciana. Generalitat Valenciana. Conselleria de Treball i Seguretat Social.

PÉREZ MARTÍN (1995): Derecho de familia. Adopción, acogimiento, tutela y otras instituciones de protección de menores. Lex Nova. Valladolid. 
MARCO LEGAL DEL ACOGIMIENTO FAMILIAR.

\begin{tabular}{|c|c|c|}
\hline Ambito Internacional & Ambito Nacional & Ambito Autonómico \\
\hline $\begin{array}{l}\text { Declaración De Los } \\
\text { Derechos Del Niño de } \\
\text { las Naciones Unidas, de } \\
20 \text { de noviembre de } \\
\text { 1959. } \\
\text { - Resolución (77) } 33 \text { del } \\
\text { Consejo de Europa so- } \\
\text { bre acogimiento de me- } \\
\text { nores. } \\
\text { - La Convención de las } \\
\text { naciones Unidas sobre } \\
\text { los Derechos del Niño } \\
\text { de 20/9/89, ratificada } \\
\text { por España el 30/12/90. } \\
\text { - CONVENIO DE LA } \\
\text { HAYA, relativo a la } \\
\text { Protección del Niño y } \\
\text { la Cooperación en ma- } \\
\text { teria de Adopción Inter- } \\
\text { nacional de 29 de mayo } \\
\text { de 1993, ratificado por } \\
\text { España el 30-6-1995 } \\
\text { (BOE de 1/8/95). }\end{array}$ & $\begin{array}{l}\text { Ley } 21 / 87 \text { de } 11 \text { de no- } \\
\text { viembre de } 1987 \text {, por la } \\
\text { que se modifican deter- } \\
\text { minados artículos del } \\
\text { Código Civil y de la } \\
\text { Ley de Enjuiciamiento } \\
\text { Civil, en materia de } \\
\text { Adopción. } \\
\text { - Ley O. 1/96 de } 15 \text { de } \\
\text { enero. De Protección } \\
\text { Jurídica del Menor, y } \\
\text { de modificación parcial } \\
\text { del C. Civil y de la } \\
\text { L.E.C. }\end{array}$ & $\begin{array}{l}\text { - Orden de } 20 / 3 / 86 \text { por la } \\
\text { que se establece el re- } \\
\text { curso de familias edu- } \\
\text { cadoras en la C. Valen- } \\
\text { ciana. } \\
\text { - Decreto } 23 / 88 \text { de medi- } \\
\text { das de protección de } \\
\text { menores en situación } \\
\text { de desamparo en la C. } \\
\text { Valenciana. } \\
\text { - Decreto } 31 / 91 \text { que mo- } \\
\text { difica algunos artículos } \\
\text { del Decreto } 23 / 88 . \\
\text { - Ley } 7 / 94 \text { de la } \\
\text { Generatilat Valenciana } \\
\text { de la Infancia. } \\
\text { - Decreto } 130 / 96 \text { de } 4 \text { de } \\
\text { Julio por el que se re- } \\
\text { gula el Consejo de } \\
\text { Adopción de Menores } \\
\text { de la Generalitat Valen- } \\
\text { ciana. } \\
\text { modifica el anterior en } \\
\text { cuanto a la composi- } \\
\text { adopción. }\end{array}$ \\
\hline
\end{tabular}

